\title{
Fabrication of Sn Coatings on Alumina Balls by Mechanical Coating Technique and Relevant Process Analysis
}

\author{
Liang Hao, Yun Lu, Hiromasa Sato, Kazuki Chiba \\ School \& Faculty of Engineering, Chiba University, Chiba, Japan \\ Email: hl.resaca.jcu@gmail.com, luyun@faculty.chiba-u.jp
}

Received 2012

\begin{abstract}
Sn coatings were fabricated by mechanical coating technique for the first time. The coatings were characterized by XRD and SEM, among others. The SEM showed that the coatings had an irregular and uneven morphology. The influence of the rotation speed of planetary ball mill on the evolution and formation of the coatings was also investigated. The results indicated that continuous Sn coatings can be formed under a moderate rotation speed. In other words, the coatings cannot be formed when rotation speed was too high or too low. The evolution of the coatings was examined and discussed. The results showed that it followed the universal evolution law of metal coatings which included four stages. However, the exfoliation of the coatings was not seen even the milling time reached $30 \mathrm{~h}$.
\end{abstract}

Keywords: Sn Coatings; Mechanical Coating Technique; Adhesion; Cold Welding; Film Evolution

\section{Introduction}

To develop nickel-based superalloy for gas turbine application, Benjamin and his colleagues at the International Nickel Company (INCO) developed mechanical alloying, well known as ball milling around 1966. Since then, ball milling has been developed to prepare a variety of equilibrium and non-equilibrium alloy phases that cannot or were difficult to be prepared by traditional techniques [1]. The non-equilibrium phases synthesized include supersaturated solid solutions, metastable crystalline and quasicrystalline phases, nanostructures and amorphous alloys, among others. Our group developed a novel coating technique derived from ball milling to prepare metal (alloy) coatings and $\mathrm{TiO}_{2}$ /metal composite photocatalyst coatings and named it mechanical coating technique (MCT) $[2,3]$. MCT is based on the principle of collision, friction and abrasion among grinding mediums and milled powders during ball milling. By this technique, Ti-Al coatings [4], Fe-Si coatings [5], Cu-Ni solid solution coatings [6], were prepared by other researchers. We also fabricated $\mathrm{Cu}$ coatings [7], Fe coatings [8] and Zn coatings [9] on alumina balls by MCT and investigated the evolution of these coatings. However, a universal law for evolution of metal coatings during the process of mechanical coating is still unknown. The influence of a series of processing parameters including rotation speed on the evolution and formation of metal coatings still needs to clarify. The influence of the intrinsic properties of metal powder on the evolution and formation of the coatings are also important not only for mechanical coating technique but also for mechanical alloying and mechanical pulverization.

The aim of this paper is to try preparing continuous Sn coatings by mechanical coating technique. In addition, we will try to summarize the universal law for the evolution of metal coatings during mechanical coating process. The influence of rotation speed on the evolution and formation of the coatings will be studied.

\section{Experimental}

\subsection{Fabrication of Sn Coatings}

35 g Sn powder (apparent density: $3.72 \mathrm{~g} / \mathrm{cm}^{3}$ ) and $30 \mathrm{~g} \mathrm{Al}_{2} \mathrm{O}_{3}$ balls (average diameter: $1 \mathrm{~mm}$ ) were used as the coating material and the substrates respectively. They were charged into a bowl made of alumina with a dimension of $\Phi 75 \mathrm{~mm} \times 70 \mathrm{~mm}$ (250 ml). The mechanical coating was then performed by a planetary ball mill (Pulverisette 6, Fritsch). To investigate the influence of the rotation speed, the rotation speed of the planetary ball mill was set between 100 and $300 \mathrm{rpm}$. The milling time was from 4 to $40 \mathrm{~h}$. To ensure the safety of mechanical milling process, a 10-minute milling operation was followed by a 2-minute cooling interval in order to avoid an excessive heating of the bowl although a temperature rise may promote the welding between metal powder particles. The schematic diagram of mechanical coating can be seen in our early work [8].

\subsection{Characterization}

Before the characterization of all the Sn-coated $\mathrm{Al}_{2} \mathrm{O}_{3}$ balls, they were treated by ultrasonic cleaning (frequency: $28 \mathrm{kHz}$ ) in acetone to remove the $\mathrm{Sn}$ particles that did not strongly adhere to $\mathrm{Al}_{2} \mathrm{O}_{3}$ balls. The phase composition and the change of the surface coverage of $\mathrm{Al}_{2} \mathrm{O}_{3}$ balls with $\mathrm{Sn}$ was examined by a $\mathrm{XRD}$ analyzer (JDX-3530, JEOL) with $\mathrm{Cu} \mathrm{K} \alpha$ radiation at 30 $\mathrm{kV}$ and $20 \mathrm{~mA}$. The surface morphologies and the microstructures of the cross sections of the Sn-coated $\mathrm{Al}_{2} \mathrm{O}_{3}$ balls were observed by SEM (JSM-6510, JEOL).

\section{Results and Discussion}

\subsection{Fabrication and Evolution of Sn Coatings}

The XRD patterns of the Sn-coated $\mathrm{Al}_{2} \mathrm{O}_{3}$ balls after the mechanical coating at $150 \mathrm{rpm}$ for different milling times are given 
in Figure 1. From these figures, the diffraction peaks of alumina can be seen although they were rather weak when milling time was $4 \mathrm{~h}$. With the increase of milling time to $8 \mathrm{~h}$, the peaks of alumina cannot be seen any more while those of tin were rather strong. It means that the surfaces of $\mathrm{Al}_{2} \mathrm{O}_{3}$ balls were totally coated with $\mathrm{Sn}$ particles. In other words, continuous $\mathrm{Sn}$ coatings might be formed at that time. With further increase of milling time to $20 \mathrm{~h}$, the peaks of alumina still did not appear. It suggests that continuous Sn coatings were not destroyed and hence the surfaces of $\mathrm{Al}_{2} \mathrm{O}_{3}$ balls were not exposed.

The SEM images of the cross sections of the Sn-coated $\mathrm{Al}_{2} \mathrm{O}_{3}$ balls after the mechanical coating at 150 rpm for different milling times are shown in Figure 2. It can be seen that discontinuous Sn coatings were formed when milling time was $4 \mathrm{~h}$. When it came to $8 \mathrm{~h}$, totally continuous Sn coatings were formed. With further increase of milling time, the thickness of the coatings was increased. The SEM images of the surface morphologies of the Sn-coated $\mathrm{Al}_{2} \mathrm{O}_{3}$ balls after the mechanical coating at 150 rpm for different milling times are given in Figure 3. As discussed in Figure 1 and Figure 2, discontinuous Sn coatings were formed when milling time was $4 \mathrm{~h}$. Continuous coatings were formed when it came to $8 \mathrm{~h}$. It can be found that the surfaces of the coatings were rather uneven and many bulges of Sn particles were also formed. With further increase of milling time, the coatings became relatively even and the bulges of Sn particles seemed not obvious. The morphology change of the coating should relate to the collision and friction among the $\mathrm{Al}_{2} \mathrm{O}_{3}$ balls coated with $\mathrm{Sn}$ and the inner wall of the bowl. Under repeated and great collision force and friction force, Sn bulges were flattened or worn down.

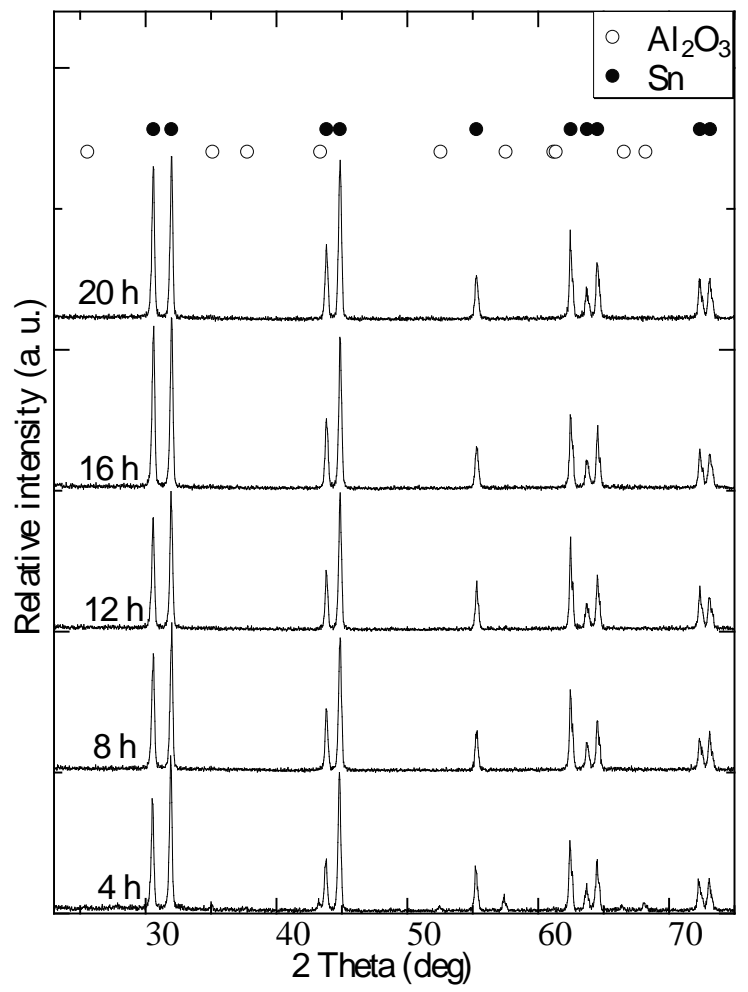

Figure 1. XRD patterns of the Sn-coated $\mathrm{Al}_{2} \mathrm{O}_{3}$ balls after the mechanical coating at $150 \mathrm{rpm}$ for different milling times.
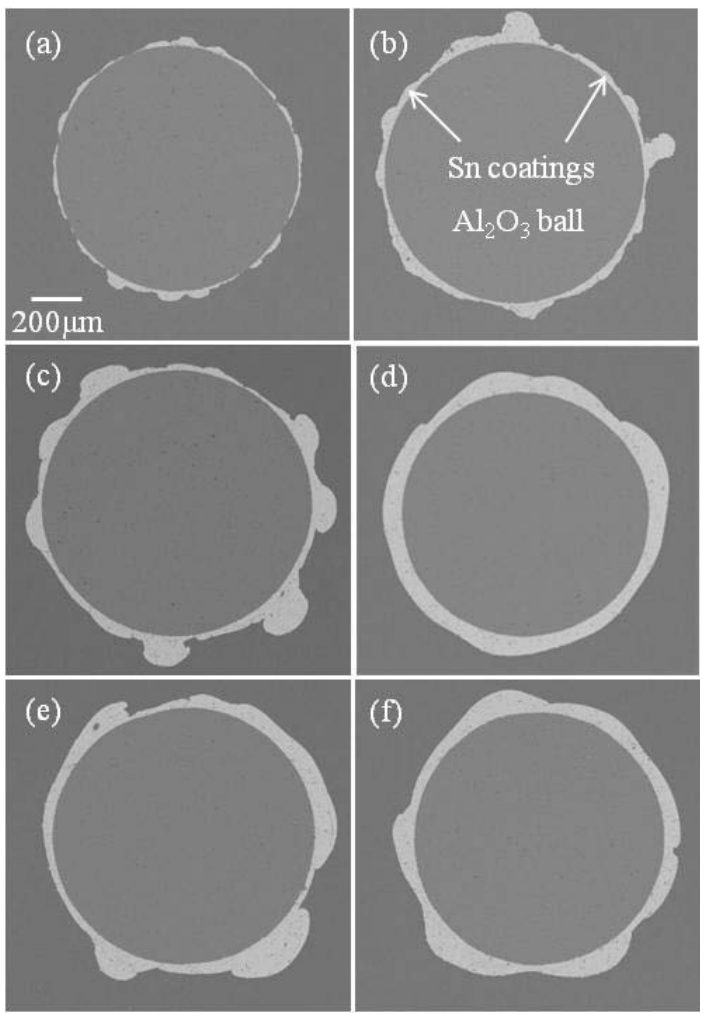

Figure 2. SEM images of the cross sections of the Sn-coated $\mathrm{Al}_{2} \mathrm{O}_{3}$ balls after the mechanical coating at $150 \mathrm{rpm}$ for different milling times: (a) 4 h, (b) 8 h, (c) 12 h, (d) 16 h, (e) 20 h and (f) 30 h.
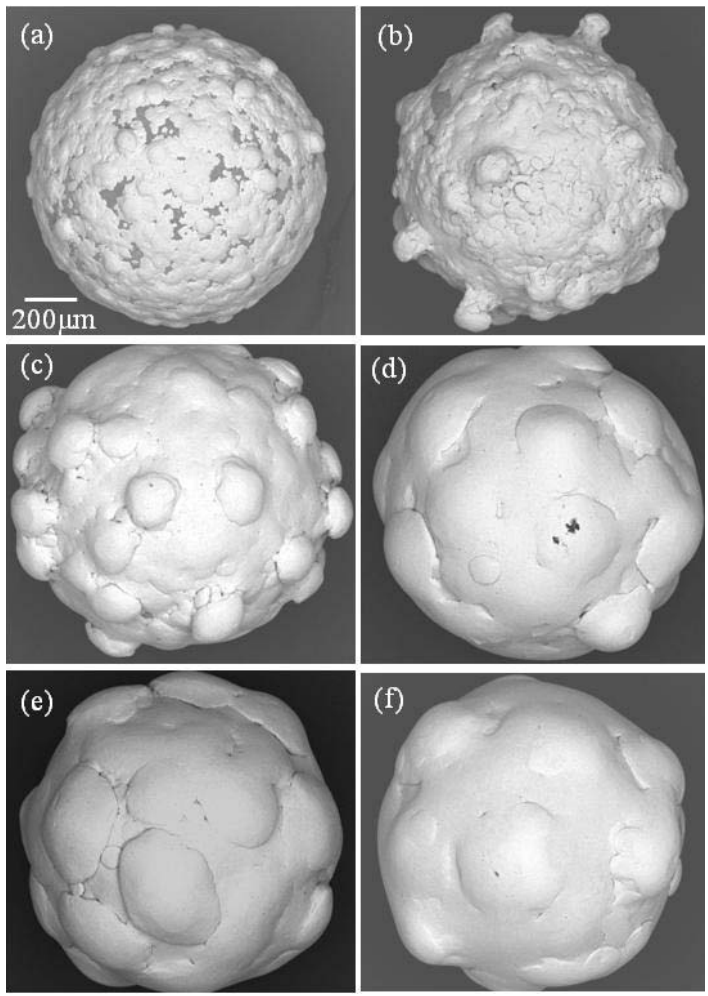

Figure 3. Surface morphologies of the Sn-coated $\mathrm{Al}_{2} \mathrm{O}_{3}$ balls after the mechanical coating at $150 \mathrm{rpm}$ for different milling times: (a) 4 h, (b) 8 h, (c) 12 h, (d) 16 h, (e) $20 \mathrm{~h}$ and (f) $30 \mathrm{~h}$. 
The evolution of Fe coatings and Zn coatings can be divided into the following stages: nucleation, formation and coalescence of discrete islands, formation and thickening of continuous coatings, and exfoliation of continuous coatings [8,9]. Although the first three stages were observed for Sn coatings, the last stage "exfoliation of continuous coatings" was not seen. The phenomenon is similar to that of $\mathrm{Cu}$ coatings [7]. It may relate to the mechanical properties of metal powders. If the milling time is prolonged, the last stage may be seen for $\mathrm{Cu}$ coatings and Sn coatings. Therefore, a universal law for the evolution of metal coatings during mechanical coating can be concluded as the above four stages of Fe and Zn coatings. For different metal powder, the holding time for each stage may be different and even certain stage(s) will not occur if milling time is not long enough such as Cu coatings and Sn coatings.

\subsection{Influence of Rotation Speed}

To investigate the influence of rotation speed on the evolution and formation of Sn coatings, we performed a series of contrast experiments in which the rotation speed was set at 100, 150, 200 and $300 \mathrm{rpm}$. When the rotation speeds was 100 and 300 rpm, continuous Sn coatings were not formed although milling time was prolonged to $40 \mathrm{~h}$. It can be confirmed that continuous Sn coatings cannot be formed at 100 and 300 rpm. Figure 4 shows the SEM images of the cross sections of the Sn-coated $\mathrm{Al}_{2} \mathrm{O}_{3}$ balls after the mechanical coating at 200 rpm for different milling times. It can be seen that discrete islands of Sn were formed when milling time was $4 \mathrm{~h}$. When it came to $8 \mathrm{~h}$, the discrete islands connected with each other. With further increase of milling time, continuous coatings were formed when milling time added up to $20 \mathrm{~h}$. Compared with the case with 150 rpm; the formation of Sn coatings took more time when rotation speed was $200 \mathrm{rpm}$.
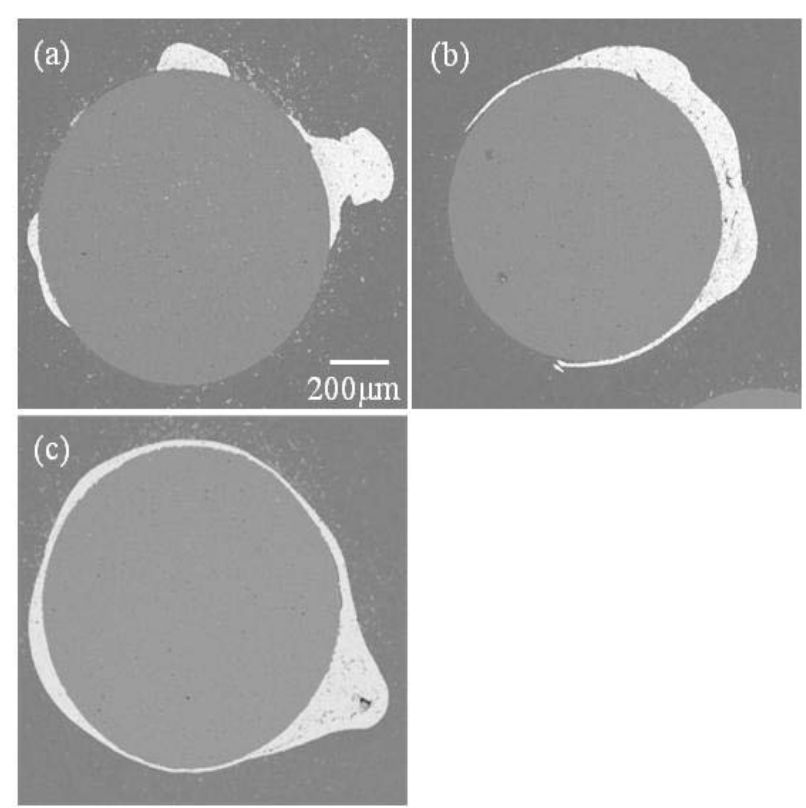

Figure 4. SEM images of the cross sections of the Sn-coated $\mathrm{Al}_{2} \mathrm{O}_{3}$ balls after the mechanical coating at $200 \mathrm{rpm}$ for different milling times: (a) $4 \mathrm{~h}$, (b) $8 \mathrm{~h}$ and (c) $20 \mathrm{~h}$.
From the above discussion, rotation speed has great effect on the evolution and formation of Sn coatings. Continuous Sn coatings can be formed during the mechanical coating with a moderate rotation speed. A similar conclusion can also be drawn for Fe coatings [8]. However, higher rotation speed can accelerate the formation of $\mathrm{Zn}$ coatings [9].

The evolution of Sn powder particles during the mechanical coating was also monitored. Figure 5 shows the SEM images of Sn powder particles before and after the mechanical coating at $150 \mathrm{rpm}$ for different milling times. From these images, the diameter of Sn powder particles became greater with the increase of milling time. These particles became spherical or lamellar from irregular shape. As discussed in the published works $[8,9]$, the diameter increase and shape change of the powder particles should result from the collision and friction among the $\mathrm{Al}_{2} \mathrm{O}_{3}$ balls and the inner wall of the bowl.

During repeated collision, Sn powder particles were trapped between the $\mathrm{Al}_{2} \mathrm{O}_{3}$ balls and the inner wall of the bowl. Under great impact force, some particles adhered to the surfaces of $\mathrm{Al}_{2} \mathrm{O}_{3}$ balls. That made the formation of $\mathrm{Sn}$ coatings on the surfaces of $\mathrm{Al}_{2} \mathrm{O}_{3}$ balls possible. The adhesion between metal particles and $\mathrm{Al}_{2} \mathrm{O}_{3}$ balls will not be involved here since it has been discussed in our unpublished work [10]. Cold welding made the particles adhered with each other and hence their diameter got larger. It should be pointed out that cold welding may happen only when the strain of metal particles is greater than a critical value [11]. A greater collision force can be obtained under a higher rotation speed and a greater collision force can produce a larger strain [9]. Therefore, cold welding tends to occur during mechanical coating at a higher rotation speed. It explains why continuous Sn coating was formed at
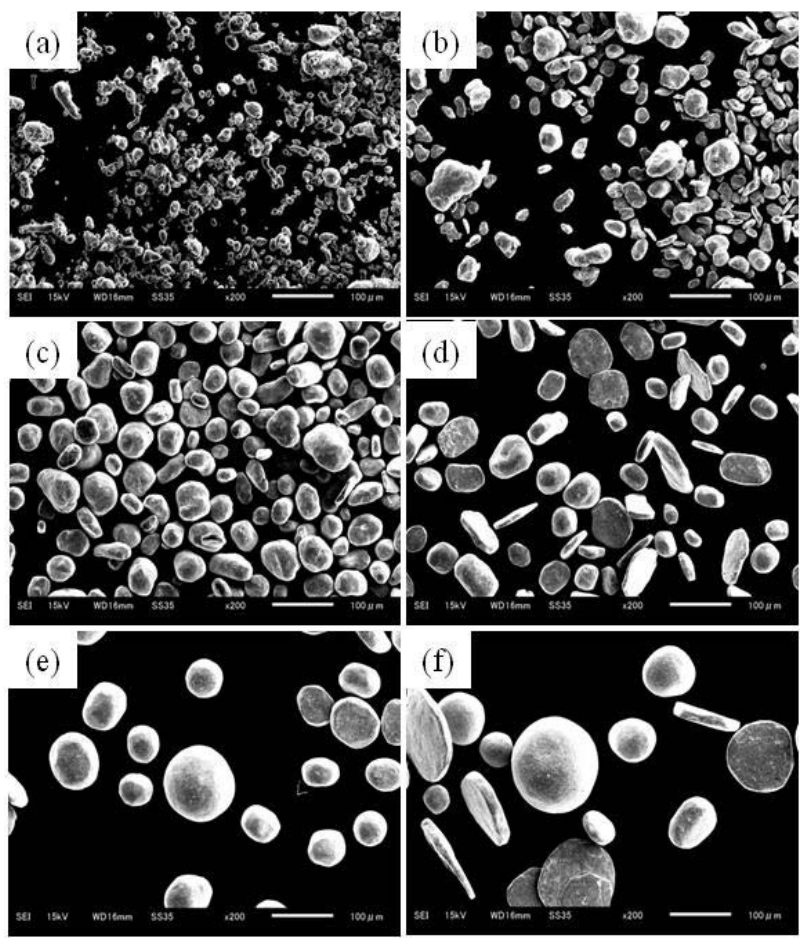

Figure 5. Evolution of Sn powder particles before and after the mechanical coating at $150 \mathrm{rpm}$ for different milling time: (a) before mechanical coating, (b) 4 h, (c) 8 h, (d) 12 h, (e) 16 h and (f) $20 \mathrm{~h}$. 
150 and $200 \mathrm{rpm}$ but did not form at $100 \mathrm{rpm}$. However, cold welding among Sn powder particles was greatly accelerated when the rotation speed was increased to $300 \mathrm{rpm}$. It can be confirmed from the significantly increase of Sn particle diameter after mechanical coating at $300 \mathrm{rpm}$. However, the adhesion of $\mathrm{Sn}$ particles to the surfaces of $\mathrm{Al}_{2} \mathrm{O}_{3}$ balls was not accelerated due to the increase of rotation speed. Therefore, Sn particles had grown up before the adhesion of the particles to $\mathrm{Al}_{2} \mathrm{O}_{3}$ balls. It is the reason why the diameter of $\mathrm{Sn}$ particles was largely increased but continuous Sn coatings on $\mathrm{Al}_{2} \mathrm{O}_{3}$ balls was not formed when rotation speed was $300 \mathrm{rpm}$. The deformation of $\mathrm{Sn}$ particles between $\mathrm{Al}_{2} \mathrm{O}_{3}$ balls and the inner wall of the bowl can be regarded as the forging between two parallel plates because the volume of the trapped Sn particles was much smaller than the colliding bodies. Therefore, lamellar particles were formed. Under collision force and friction force, the sharp corners of the particles were eliminated and hence large spherical particles appeared.

From the above analysis about the influence of rotation speed, the formation of metal coatings on the surfaces of $\mathrm{Al}_{2} \mathrm{O}_{3}$ balls includes two kinds of interaction: the adhesion of metal particles to the surfaces of $\mathrm{Al}_{2} \mathrm{O}_{3}$ balls and then the cold welding between metal particles. If we want to prepare metal coatings on $\mathrm{Al}_{2} \mathrm{O}_{3}$ balls, we have to find out the metals which tend to adhere to the surfaces of $\mathrm{Al}_{2} \mathrm{O}_{3}$ and easy to weld with each other.

\section{Collisions}

Continuous $\mathrm{Sn}$ coatings were fabricated on $\mathrm{Al}_{2} \mathrm{O}_{3}$ balls by mechanical coating technique. The results of XRD and SEM indicate that the evolution of the coatings follows a universal law for the evolution of metal coatings which includes the following stages: nucleation, formation and coalescence of discrete islands, formation and thickening of continuous coatings, and exfoliation of continuous coatings. Continuous Sn coatings can be prepared during the mechanical coating at a moderate rotation speed such as 150 and $200 \mathrm{rpm}$ but cannot be formed at higher or lower ones such as 300 and $100 \mathrm{rpm}$. The influence of rotation speed should relate to the adhesion of metal powder particles to the surfaces of $\mathrm{Al}_{2} \mathrm{O}_{3}$ balls and the cold welding among metal powder particles.

\section{Acknowledgements}

The authors gratefully acknowledge the financial support from Denshi-Jisso Company in Japan. The authors would like to thank Fukuda metal foil \& powder Co., Ltd. of Japan for providing us with the Sn powder used in the work.

\section{REFERENCES}

[1] C. Suryanarayana, "Mechanical alloying and milling," Prog. Mater. Sci. vol. 46, pp. 1-184, January 2001.

[2] H. Yoshida, Y. Lu, H. Nakayama and M. Hirohashi, "Formation of $\mathrm{TiO}_{2}$ film by mechanical coating technique and its photocatalyst activity,” J. Alloy. Compd., vol. 475, pp. 383-386, May 2009.

[3] Y. Lu, H. Yoshida, H. Nakayama, L. Hao and M. Hirohashi, "Formation of $\mathrm{TiO}_{2} / \mathrm{Ti}$ composite photocatalyst film by 2-step mechanical coating technique,” Mater. Sci. Forum, vol. 675-677, pp. 1229-1232, February 2011

[4] S. Romankov, W. Sha, S.D. Kaloshkin and K. Kaevitser, "Formation of Ti-Al coatings by mechancial alloying method," Surf. Coat. Tech., vol. 201, pp. 3235-3245, December 2006.

[5] G. Gupta, K. Mondal and R. Balasubramaniam, "In situ nanocrystalline Fe-Si coating by mechanical alloying,” J. Alloy. Compd., vol. 482, pp. 118-122, August 2009.

[6] I. Farahbakhsh, A. Zakeri, P. Manikandan and K. Hokamoto, "Evaluation of nanostructured coating layers formed on Ni balls during mechanical alloying of Cu powder,” Appl. Surf. Sci., vol. 257, pp. 2830-2837, January 2011.

[7] Y. Lu, L. Hao, K. Toh and H. Yoshida, "Fabrication of $\mathrm{TiO}_{2} / \mathrm{Cu}$ composite photocatalyst thin film by 2-step mechanical coating technique and its photocatalytic activity,” Adv. Mat. Res., vol. 415-417, pp. 1942-1948, February 2012.

[8] L. Hao, Y. Lu, H. Asanuma and J. Guo, "The influence of the processing parameters on the formation of iron thin films on alumina balls by mechanical coating technique,” J. Mater. Process. Tech., vol. 212, pp. 1169-1176, May 2012.

[9] L. Hao, Y. Lu, H. Asanuma and J. Guo, "Fabrication of zinc coatings on alumina balls from zinc powder by mechanical coating technique and the process analysis,” Powder Technol., vol. 228, pp. 377-384, September 2012.

[10] L. Hao, Y. Lu, H. Sato, H. Asanuma and J. Guo, "Influence of metallic properties on formation and evolution of mechanical coatings during mechanical coating technique,” unpublished.

[11] L. Lü, M.O. Lai and S. Zhang, "Modeling of the mechanical-alloying process,” J. Mater. Process. Tech., vol. 52, pp. 539-546, June- July 1995. 